\title{
Epidermal growth factor receptor is expressed and active in a subset of acute myeloid leukemia
}

\author{
Hasan Mahmud ${ }^{1 \dagger}$, Steven M. Kornblau ${ }^{2 \dagger}$, Arja ter Elst ${ }^{1}$, Frank J. G. Scherpen ${ }^{1}$, Yi Hua Qiu ${ }^{2}$, Kevin R. Coombes ${ }^{3}$ \\ and Eveline S. J. M. de Bont ${ }^{1^{*}}$
}

\begin{abstract}
The epidermal growth factor receptor (EGFR) inhibitor erlotinib has been shown to induce complete remission of acute myeloid leukemia (AML) in two patients with concurrent lung cancer and raised attention for a role of EGFR in AML whereas a recent phase II clinical study with gefitinib in AML demonstrated a negative result on the outcome. However, from several studies, EGFR expression in AML is poorly defined and the role of EGFR in AML remains unclear. Herein, we report the results of EGFR expression in AML of large cohorts of adult and pediatric AML patients with the data of total protein and phosphorylation levels of EGFR. Our data conclude that there is the expression of EGFR at the protein level in a subset of AML, which was identified to be functionally active in $~ 15 \%$ of AML patients. This suggests that future studies need to be conducted with a subset of AML patients characterized by high EGFR expression.
\end{abstract}

Keywords: EGFR, AML, RPPA, Kinome, Leukemia

Epidermal growth factor receptor (EGFR) expression in acute myeloid leukemia (AML) cells is a subject of controversy, as there is no consensus about the expression and activity of EGFR in AML. In non-small cell lung cancer (NSCLC) patients, EGFR is known to be highly expressed. The EGFR inhibitor erlotinib was shown to induce complete remission of AML in two adult patients with concurrent NSCLC and raised attention for EGFR in AML $[1,2]$. Especially NSCLC patients with rare EGFR mutations had lower response rates to EGFR inhibitors than the patients with common mutations [3], due to the counteraction of EGFR tyrosine kinase inhibitors (TKIs) with specific EGFR mutations. In AML, previous reports showed that erlotinib was able to induce in vitro differentiation, cell cycle arrest, and apoptosis of AML blasts [4]. Another study showed that gefitinib, another EGFR inhibitor, induced myeloid differentiation in

\footnotetext{
* Correspondence: e.s.j.m.de.bont@umcg.nl

${ }^{\dagger}$ Equal contributors

'Department of Pediatrics, Division of Pediatric Oncology/Hematology, Beatrix Children's Hospital, University Medical Center Groningen, University of Groningen, PO Box 30.0019700 RB Groningen, The Netherlands

Full list of author information is available at the end of the article
}

AML [5]. Additionally, EGFR expression was confirmed by an experimental murine tumor of AML origin [6]. Gene expression of larger adult and pediatric AML samples detected EGFR expression previously $[7,8]$. In contrast, EGFR protein levels, as assessed by immunochemistry, and mRNA levels of EGFR have been found to be doubtfully low in AML blasts $[9,10]$. In AML cell lines, EGFR is not expressed both at protein and mRNA levels and the phenotypic effects of the EGFR inhibitors must be due to off-target effects $[9,11]$. Recently, Deangelo et al. investigated the effect of EGFR inhibitor gefitinib in adult AML patients $(n=18)$ in a phase II clinical study [12]. Their results suggested that the single-agent gefitinib has no effect on patient outcome due to undetectable EGFR expression levels, both mRNA and protein. Therefore, data on whether EGFR is expressed, the actual level of expression, and if EGFR is present in an activated posttranslationally modified phosphorylated state in AML has not been consistent in previous studies using small subsets of AML patients. Herein, we demonstrate the EGFR expression in total protein and protein phosphorylation levels in a well-defined subset of patients in large cohorts of AML patients. 


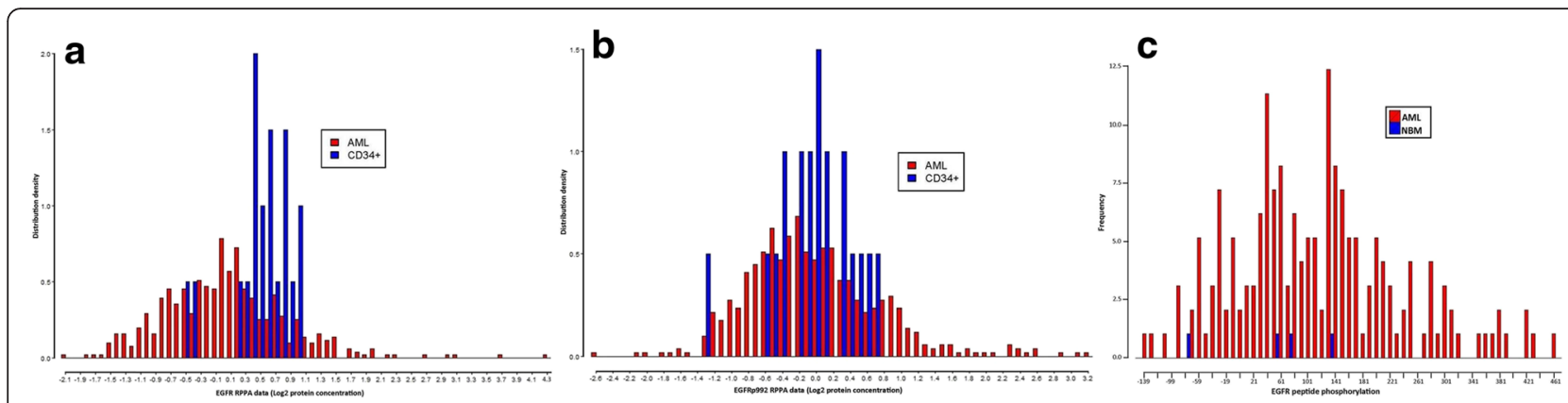

Fig. 1 The total EGFR protein expression, phosphorylation of EGFR and EGFR peptides phosphorylation in primary AML samples. a Total EGFR protein expression was measured using RPPA of 511 adult AML samples. Total EGFR protein was highly expressed in 11\% (57/511) of the adult AML samples versus the CD34+ normal bone marrow (NBM) samples. The distribution density of total EGFR expression was depicted in the figure. $\mathbf{b}$ Similarly, the EGFR protein phosphorylation levels were measured using RPPA of the same 511 adult AML samples. EGFR protein phosphorylation levels were $18 \%$ (93/511) higher in adult AML patient samples compared to the CD34+ NBM samples. c The EGFR peptide phosphorylations were measured using PepChipTM Kinomics microarray system of 179 AML patients. The median of four EGFR peptides with different phosphorylation sites was used to make the graph

We investigated total EGFR protein expression as well as EGFR phosphorylation in AML blasts using reverse phase protein array (RPPA) in a large cohort of adult AML patients $(n=511)$ and EGFR peptide phosphorylation levels using peptide phosphorylation array of AML patients both pediatric and adult $(n=96+83=179)$. The details of the sample collections and the methods of RPPA and peptide phosphorylation array are described $[13,14]$ in the design and methods section (Additional file 1: Design and methods). In this report, we demonstrate that the EGFR protein $(n=511)$ is expressed and active in a subset of AML patients. Expression of both total and Y992 phosphorylated EGFR protein was readily detected both in normal bone marrow (NBM)-derived CD34+ cells and in AML blasts, with expression following a Gaussian distribution. In the primary AML samples, expression of total EGFR protein was higher than that of NBM CD34+ cells in $11 \%$ and expression of phosphorylated EGFR exceeded NBM in $18 \%$ of cases (Fig. 1a, b). Interestingly, the total EGFR expression and EGFR phosphorylation data are correlated significantly $(p<0.0001)$. There was no significant difference of molecular and clinical characteristics (e.g., age, sex, WHO classification, FAB classification, karyotypes, blast percentage, white blood cell count, hemoglobin concentration, platelet count, complete response rate, relapse frequencies, death frequencies, FLT3-ITD, FLT3D835, and NPM1 mutations) found between the $11 \%$ AML (high EGFR) patients and the rest of the $89 \%$ AML (low EGFR) patients (Additional file 2: Table S1). In addition, EGFR tyrosine kinase is functionally active in AML blasts, as demonstrated by peptide phosphorylation activity of EGFR-related peptides using peptide phosphorylation profiling arrays in a large cohort of AML patients $(n=179)$ (Fig. 1c). These results indicate that EGFR protein is both expressed and present in activated phosphorylated forms in AML, supporting EGFR as a potential therapeutic target in EGFR-expressing AML patients. The RPPA dataset is available at http://bioinformatics.mdanderson.org/ supplements.html (under "RPPA Data in AML") and the processed raw data of peptides phosphorylation can be found in the additional information (Additional file 3: Peptide phosphorylation data for Fig. 1c).

The discordance between the readily detectable EGFR protein levels observed in this study and the lack of EGFR expression seen in some other analyses, as well as the lack of clinical efficacy of EGFR inhibitors seen in prior clinical trials, can be explained with our data. Patients included in previous studies could belong to the group of $85 \%$ of AML samples which showed the same levels of EGFR expression as normal CD34+ cells in our study. The inclusion of only patients with low expression might account for the lack of response to gefitinib in AML patients $(n=$ 18) evaluated in the phase II study by Deangelo et al. [12].

Altogether, our data shows increased expression of EGFR at both the total protein (11\%) and protein phosphorylation (18\%) levels in a subset of AML patients compared to normal CD34+ samples. Results of future clinical studies of EGFR inhibitors might be improved if they are restricted to patients with highly expressed EGFR or active phosphorylated EGFR. Notably, mutations of EGFR were not observed in the TCGA analyses of AML, so consideration of mutation status is not required in AML as it is for lung cancer [15].

\section{Additional files}

Additional file 1: Design and methods. (DOCX $15 \mathrm{~kb})$

Additional file 2: Patient characteristics. (DOCX $18 \mathrm{~kb}$ )

Additional file 3: Peptide phosphorylation data for Fig. 1c. (XLSX 22 kb) 


\section{Abbreviations}

AML, acute myeloid leukemia; EGFR, epidermal growth factor receptor; NBM, normal bone marrow; NSCLC, non-small cell lung cancer; RPPA, reverse phase protein array; TKIs, tyrosine kinase inhibitors

\section{Acknowledgements}

We would like to thank the patients who donated leukemia specimens and also physician assistances, nurse practitioners, and fellows who acquired specimens.

\section{Funding}

This work was supported by a grant from the Foundation KiKa, Amstelveen $(\mathrm{HM}, \mathrm{AtE}$, and ESJMdB). HM was supported by a grant "Stichting Beatrix Kinderziekenhuis" from the University Medical Center Groningen, The Netherlands.

\section{Availability of data and materials}

The dataset is available at http://bioinformatics.mdanderson.org/ supplements.html (under "RPPA Data in AML"). The file containing the processed raw data of peptide phosphorylation can be found in the additional information (Additional file 3).

\section{Authors' contributions}

$H M, S M K$, and ESJMdB designed the research, performed the research, collected the data, analyzed the data, and wrote the paper. AtE and FJGS designed the research, collected the data, and analyzed the data. YHQ and KRC performed the analysis and interpretation of the data. All authors read and approved the final manuscript.

\section{Competing interests}

The authors declare that they have no competing interests.

\section{Consent for publication}

Not applicable

\section{Ethics approval and consent to participate}

The AML samples of adult and pediatric AML patients were collected after getting written informed consent. This was approved by the Medical Ethical Committee of MD Anderson Cancer Center, University of Texas, USA, and of the University Medical Center Groningen, The Netherlands, in accordance with the Helsinki Declaration.

\section{Author details}

${ }^{1}$ Department of Pediatrics, Division of Pediatric Oncology/Hematology, Beatrix Children's Hospital, University Medical Center Groningen, University of Groningen, PO Box 30.0019700 RB Groningen, The Netherlands. ${ }^{2}$ Department of Stem Cell Transplantation and Cellular Therapy, MD Anderson Cancer Center, University of Texas, Houston, TX, USA. ${ }^{3}$ Department of Biomedical Informatics, Wexner Medical Center, The Ohio State University, Columbus, OH, USA.

Received: 1 June 2016 Accepted: 27 July 2016

Published online: 03 August 2016

\section{References}

1. Chan G, Pilichowska M. Complete remission in a patient with acute myelogenous leukemia treated with erlotinib for non small-cell lung cancer. Blood. 2007;110:1079-80

2. Pitini V, Arrigo C, Altavilla G. Erlotinib in a patient with acute myelogenous leukemia and concomitant non-small-cell lung cancer. J Clin Oncol. 2008;26: $3645-6$

3. Arrieta O, Cardona AF, Corrales L, Campos-Parra AD, Sánchez-Reyes R, Amieva-Rivera $\mathrm{E}$, et al. The impact of common and rare EGFR mutations in response to EGFR tyrosine kinase inhibitors and platinum-based chemotherapy in patients with non-small cell lung cancer. Lung Cancer. 2015;87:169-75.

4. Boehrer S, Ades L, Braun T, Galluzzi L, Grosjean J, Fabre C, et al. Erlotinib exhibits antineoplastic off-target effects in AML and MDS: a preclinical study. Blood. 2008;111:2170-80

5. Stegmaier K, Corsello SM, Ross KN, Wong JS, Deangelo DJ, Golub TR. Gefitinib induces myeloid differentiation of acute myeloid leukemia. Blood. 2005;106:2841-8.
6. Ben-Ishay Z. Expression of epidermal growth factor receptor by an experimental murine tumor of acute myeloid leukemia origin. Acta Haematol. 2014;131:183-6.

7. Verhaak RG, Wouters BJ, Erpelinck CA, Abbas S, Beverloo HB, Lugthart S, Löwenberg B, Delwel R \& Valk PJ. Prediction of molecular subtypes in acute myeloid leukemia based on gene expression profiling. Haematologica. 2009; 94:131-4. (http://www.ncbi.nlm.nih.gov/geo, accession number GSE6891).

8. de Jonge HJ, Valk PJ, Veeger NJ, ter Elst A, den Boer ML, Cloos J, de Haas V, van den Heuvel-Eibrink MM, Kaspers GJ, Zwaan CM, Kamps WA, Löwenberg $B$ \& de Bont ES. High VEGFC expression is associated with unique gene expression profiles and predicts adverse prognosis in pediatric and adult acute myeloid leukemia. Blood. 2010;116:1747-54. (http://www.ncbi.nlm.nih. gov/geo, accession number GSE22056).

9. Lindhagen E, Eriksson A, Wickstrom M, Danielsson K, Grundmark B, Henriksson R, et al. Significant cytotoxic activity in vitro of the EGFR tyrosine kinase inhibitor gefitinib in acute myeloblastic leukaemia. Eur J Haematol. 2008;81:344-53.

10. Sun JZ, Lu Y, Xu Y, Liu F, Li FQ, Wang QL, et al. Epidermal growth factor receptor expression in acute myelogenous leukaemia is associated with clinical prognosis. Hematol Oncol. 2012;30:89-97.

11. Boehrer S, Galluzzi L, Lainey E, Bouteloup C, Tailler M, Harper F, et al. Erlotinib antagonizes constitutive activation of SRC family kinases and mTOR in acute myeloid leukemia. Cell Cycle. 2011;10:3168-75.

12. Deangelo DJ, Neuberg D, Amrein PC, Berchuck J, Wadleigh M, Sirulnik LA, et al. A phase II study of the EGFR inhibitor gefitinib in patients with acute myeloid leukemia. Leuk Res. 2014;38:430-4.

13. Kornblau SM, Tibes R, Qiu YH, Chen W, Kantarijan HM, Andreeff M, et al. Functional proteomic profiling of AML predicts response and survival. Blood. 2009;113:154-64.

14. Kampen KR, Ter Elst A, Mahmud H, Scherpen FJ, Diks SH, Peppelenbosch MP, et al. Insights in dynamic kinome reprogramming as a consequence of MEK inhibition in MLL-rearranged AML. Leukemia. 2014;28:589-99.

15. Ley TJ, Miller C, Ding L, Raphael BJ, Mungall AJ, Robertson A, et al. Genomic and epigenomic landscapes of adult de novo acute myeloid leukemia. $\mathrm{N}$ Engl J Med. 2013;368(22):2059-74.

\section{Submit your next manuscript to BioMed Central and we will help you at every step:}

- We accept pre-submission inquiries

- Our selector tool helps you to find the most relevant journal

- We provide round the clock customer support

- Convenient online submission

- Thorough peer review

- Inclusion in PubMed and all major indexing services

- Maximum visibility for your research

Submit your manuscript at www.biomedcentral.com/submit
) Biomed Central 